\title{
Assessment of esophageal carcinoma undergoing concurrent chemoradiotherapy with quantitative dynamic contrast-enhanced magnetic resonance imaging
}

\author{
JING LEI ${ }^{1,2^{*}}$, QIAN HAN ${ }^{2 *}$, SHAOCHENG ZHU ${ }^{2}$, DAPENG SHI ${ }^{2}$, SHEWEI DOU ${ }^{2}$, ZIHUA SU $^{3}$ and XIAO XU ${ }^{3}$ \\ ${ }^{1}$ Graduate School, Xinxiang Medical University, Xinxiang, Henan 453003; \\ ${ }^{2}$ Department of Radiology, Henan Provincial People's Hospital, Zhengzhou, Henan 450003; \\ ${ }^{3}$ Department of Premium Application, GE Healthcare Life Sciences, Beijing 100176, P.R. China
}

Received October 26, 2014; Accepted August 17, 2015

DOI: $10.3892 / \mathrm{ol} .2015 .3779$

\begin{abstract}
The aim of the present study was to investigate whether quantitative dynamic contrast-enhanced magnetic resonance imaging (DCE-MRI) can predict an early response in primary esophageal carcinoma patients undergoing concurrent chemoradiotherapy. A total of 25 patients with who were pathologically confirmed stage II-III esophageal carcinoma underwent quantitative DCE-MRI prior to chemoradiotherapy, and at 3 weeks post-treatment, the quantitative parameters [ $\mathrm{K}^{\text {trans }}$ (volume transfer constant; the rate at which contrast agent distributes from the plasma to the $\mathrm{EES}$ ), $\mathrm{K}_{\mathrm{ep}}$ (rate contrast; the rate at which the contrast agent that has diffused to the EES returns to the plasma) and $V_{e}$ (the contrast agent percentage in the space of the extracellular fluid)] were analyzed respectively. The 25 cases were categorized as a complete response (CR) or a partial response (PR). An independent samples Mann-Whitney U test was used to compare the quantitative parameters between $\mathrm{CR}$ and PR. A receiver operating characteristic curve (ROC) was used to determine the best predictor. In total, 17 patients were in the CR group and 8 patients were in the PR group. Pretreatment $\mathrm{K}^{\text {trans }}, \mathrm{K}_{\mathrm{ep}}$ and $\mathrm{V}_{\mathrm{e}}$ values were $0.54 \pm 0.17 / \mathrm{min}$, $1.12 \pm 0.46 / \mathrm{min}$ and $0.37 \pm 0.14$, respectively, in the CR group, and $0.40 \pm 0.21 / \mathrm{min}, 1.07 \pm 0.37 / \mathrm{min}$ and $0.40 \pm 0.22$, respectively, in the PR group. There was a significant difference between the two groups for $\mathrm{K}^{\text {trans }}$, but there were no significant differences between the two groups for $\mathrm{K}_{\mathrm{ep}}$ and $\mathrm{V}_{\mathrm{e}}$.
\end{abstract}

Correspondence to: Dr Shaocheng Zhu, Department of Radiology, Henan Provincial People's Hospital, 7 Weiwu Road, Zhengzhou, Henan 450003, P.R. China

E-mail: shaochengzhucn@163.com

*Contributed equally

Key words: esophageal carcinoma, quantitative dynamic contrast-enhanced magnetic resonance imaging, concurrent chemoradiotherapy
The $\mathrm{K}^{\text {trans }}, \mathrm{K}_{\mathrm{ep}}$ and $\mathrm{V}_{\mathrm{e}}$ values at 3 weeks post-treatment were $0.33 \pm 0.11 / \mathrm{min}, 0.86 \pm 0.31 / \mathrm{min}$ and $0.66 \pm 0.05$, respectively, in the CR group, and $0.62 \pm 0.22 / \mathrm{min}, 1.19 \pm 0.39 / \mathrm{min}$ and $0.45 \pm 0.19$, respectively, in the PR group. The corresponding $\mathrm{U}$ values were $-3.319,-1.719$ and -2.628 , respectively, and the P-values were $0.006,0.119$ and 0.021 , respectively. The areas under the ROC curve of $\mathrm{K}^{\text {trans }}$ prior to chemoradiotherapy, and of $\mathrm{K}^{\text {trans }}$ and $\mathrm{K}_{\mathrm{ep}}$ at 3 weeks post-treatment were 0.648 , 0.741 and 0.796 , respectively. In conclusion, DCE-MRI can predict an early response in primary esophageal carcinoma following 3 weeks of concurrent chemoradiotherapy. $\mathrm{K}^{\text {trans }}$ prior to chemoradiotherapy, and $\mathrm{K}^{\text {trans }}$ and $\mathrm{K}_{\mathrm{ep}}$ at 3 weeks post-treatment are sensitive prediction parameters.

\section{Introduction}

Esophageal carcinoma is a common disease, and $>80 \%$ of cases occur in developing countries. In 2008, esophageal cancer was the eighth most common cancer worldwide and China was ranked with the fourth highest morbidity rate for esophageal cancer worldwide with a five-year survival rate of $<40 \%$ (1). The early symptoms of the disease, which include difficulty swallowing and esophageal foreign body sensation, are not obvious, and thus the majority of patients are diagnosed at an advanced stage (2). At present, the most common diagnostic techniques involve the examination of esophageal function, and include imaging analysis and esophagoscopy (3). The current treatment methods for esophageal carcinoma include surgery, radiation therapy, chemotherapy, endoscopic therapy and combined therapy. Patients with early-stage disease are usually treated with surgery, while patients with advanced esophageal carcinoma or unresectable tumors are administered synchronous radiotherapy and chemotherapy, which may increase the survival rate of patients (4).

The quantity of new vessels in a tumor and the permeability of the vessel walls can reflect the activity of the tumor tissues. Concurrent chemoradiotherapy can inhibit the expression of vascular endothelial growth factor (VEGF) effectively, thus preventing the regeneration of new vessels in a tumor (5-7). Quantitative dynamic contrast-enhanced 
magnetic resonance imaging (DCE-MRI) takes advantage of dynamic enhancement and pharmacokinetic theory, and measures the $\mathrm{K}^{\text {trans }}$ (volume transfer constant; the rate at which contrast agent distributes from the plasma to the EES), $\mathrm{K}_{\mathrm{ep}}$ (rate contrast; the rate at which the contrast agent that has diffused to the EES returns to the plasma) and $\mathrm{V}_{\mathrm{e}}$ (the contrast agent percentage in the space of the extracellular fluid) values in the region of interest (ROI) to monitor the condition in which the contrast agent penetrates the vessel wall and the distribution of the contrast agent in the extravascular extracellular space (EES) $(8,9)$. The present study describes a novel approach for assessing functional parameters; a DCE-MRI double ventricle model technique was used to analyze the variation of quantitative parameters in patients with stage II-III esophageal carcinoma prior to chemoradiotherapy and at 3 weeks post-treatment, in order to investigate whether quantitative DCE-MRI can predict an early response in primary esophageal carcinoma patients undergoing concurrent chemoradiotherapy.

\section{Subjects and methods}

Subjects. A total of 32 patients with stage II-III esophageal cancer who had undergone concurrent chemoradiotherapy at Henan Provincial People's Hospital (Zhengzhou, China) between April 2013 and April 2014 were included in this study. The inclusion criteria were: i) Patients were pathologically confirmed with stage II-III esophageal squamous carcinoma by esophagoscopy; ii) patients underwent DCE-MRI using the same equipment prior to chemoradiotherapy and at 3 weeks post-treatment; and iii) patients underwent esophageal carcinoma clinical and imaging response evaluation 1 month after finishing all the treatment courses. An ROI could not be set in 2 cases due to the large range of necrosis inside the tumor. The artifacts of another 2 cases were serious when moving. A further 3 cases failed the imaging test. Finally, 25 cases were selected, including 16 men and 9 women. The age varied from 52 to 80 years, and the mean age was 68 years. This study was conducted in accordance with the declaration of Helsinki. This study was conducted with approval from the Ethics Committee of Henan Provincial People's Hospital. Written informed consent was obtained from all participants.

Inspection methods. A 3.0T Discovery $750 \mathrm{MR}$ scanner and 8-channel body special phased array coil designed by General Electric Company (GE Healthcare, Bethesda, MD, USA) was utilized. Electrocardiograph and respiratory gating were adopted by patients who could breathe normally, and single-shot was adopted by patients who could not breathe normally. Patients were maintained in the supine position, and underwent shallow and slow abdominal respiration training prior to treatment. In normal conditions, a transverse view was obtained by T2-weighted imaging (T2WI) and T1W1, and a sagittal view was obtained by T2WI scanning. DCE-MRI was performed using the liver acquisition with volume acceleration sequence, and the scanning parameters were as follows: Repetition time, $4 \mathrm{msec}$; echo time, $1.9 \mathrm{msec}$; depth of stratum, $3.8 \mathrm{~mm}$; interlayer spacing, $1.8 \mathrm{~mm}$; field of view, 34x34 cm; and matrix, 256x192. Gadodiamide, a gadolinium-based contrast agent was injected at a dose of
$0.5 \mathrm{mmol} / \mathrm{kg}$. An Ulrich Missouri (Ulrich Medical, Ulm, Germany) injector was used for the injection at a speed of $3.0 \mathrm{ml} / \mathrm{sec}$ through the detained trocar of the elbow vein before, then $25 \mathrm{ml}$ normal saline was used as a bolus injection to wash this through. Patients were scanned for 6 periods (6 sec each) prior to injecting the contrast agent, then scanning was continued for 54 periods. A total of 60 periods and 960 images were collected, as every period included 16 images. MRI scans were performed 1 month after finishing all the treatment courses. The sequence and parameters were the same prior to chemoradiotherapy and at 3 weeks post-treatment.

Measurement and calculation of parameter values. All the original data was transmitted to an ADW 4.5 workstation (GE Healthcare), and the Cintool software (GE Healthcare) hemodynamics Tofts two compartment model measured and calculated the parameter values. Two experienced abdominal imaging doctors set the ROI manually. Specific methods used included referring to the warm areas in $\mathrm{K}^{\text {trans }}, \mathrm{K}_{\mathrm{ep}}$ and $\mathrm{V}_{\mathrm{e}}$, and moving the ROI in DCE-MRI until the maximal values of $\mathrm{K}^{\text {trans }}, \mathrm{K}_{\mathrm{ep}}$ and $\mathrm{V}_{\mathrm{e}}$ were obtained. Areas of cystic change, necrosis and hemorrhage, and areas containing normal vessels were avoided when setting the ROI. The positions of the two ROIs were at the same phases, layers and locations prior to chemoradiotherapy and at 3 weeks post-treatment.

Curative effect evaluation criteria. The maximal diameters of the tumor were measured respectively in MRI scanning images prior to chemoradiotherapy and at 3 weeks post-treatment. According to the Response Evaluation Criteria In Solid Tumors (10), the patients was divided into those with tumors exhibiting a complete response (CR) and those with a partial response (PR).

Statistical analysis. SPSS 19.0 statistical software (SPSS Inc., Chicago, IL, USA) was used to compare the variation of quantitative parameters between the CR and PR groups prior to chemoradiotherapy and at 3 weeks post-treatment. Two independent sample Mann-Whitney U tests were adopted. $\mathrm{P}<0.05$ indicated that the differences were statistically significant. The ROC of the $\mathrm{K}^{\text {trans }}, \mathrm{K}_{\mathrm{ep}}$ and $\mathrm{V}_{\mathrm{e}}$ parameter values prior to chemoradiotherapy and at 3 weeks post-treatment was drawn to obtain the area under the curve and the maximal Youden's index, thus finding out the best parameter for predicting an early response in primary esophageal carcinoma, and its diagnostic susceptibility and specificity.

\section{Results}

Among the 25 patients with stage II-III esophageal carcinoma, 17 cases were designated to the CR group (Fig. 1) and 8 cases were designated to the PR group (Fig. 2). Among the parameters, for pseudocolor images, if the color was warmer, the parameter value $\left(\mathrm{K}_{\mathrm{ep}}\right)$ would be higher; otherwise, the parameter value would be lower.

No statistically significant difference in parameter values was identified between the 2 groups prior to chemoradiotherapy (Table I). At 3 weeks post-treatment, the values of $\mathrm{K}^{\text {trans }}$ and $\mathrm{K}_{\mathrm{ep}}$ in the $\mathrm{CR}$ group decreased, but the values of 

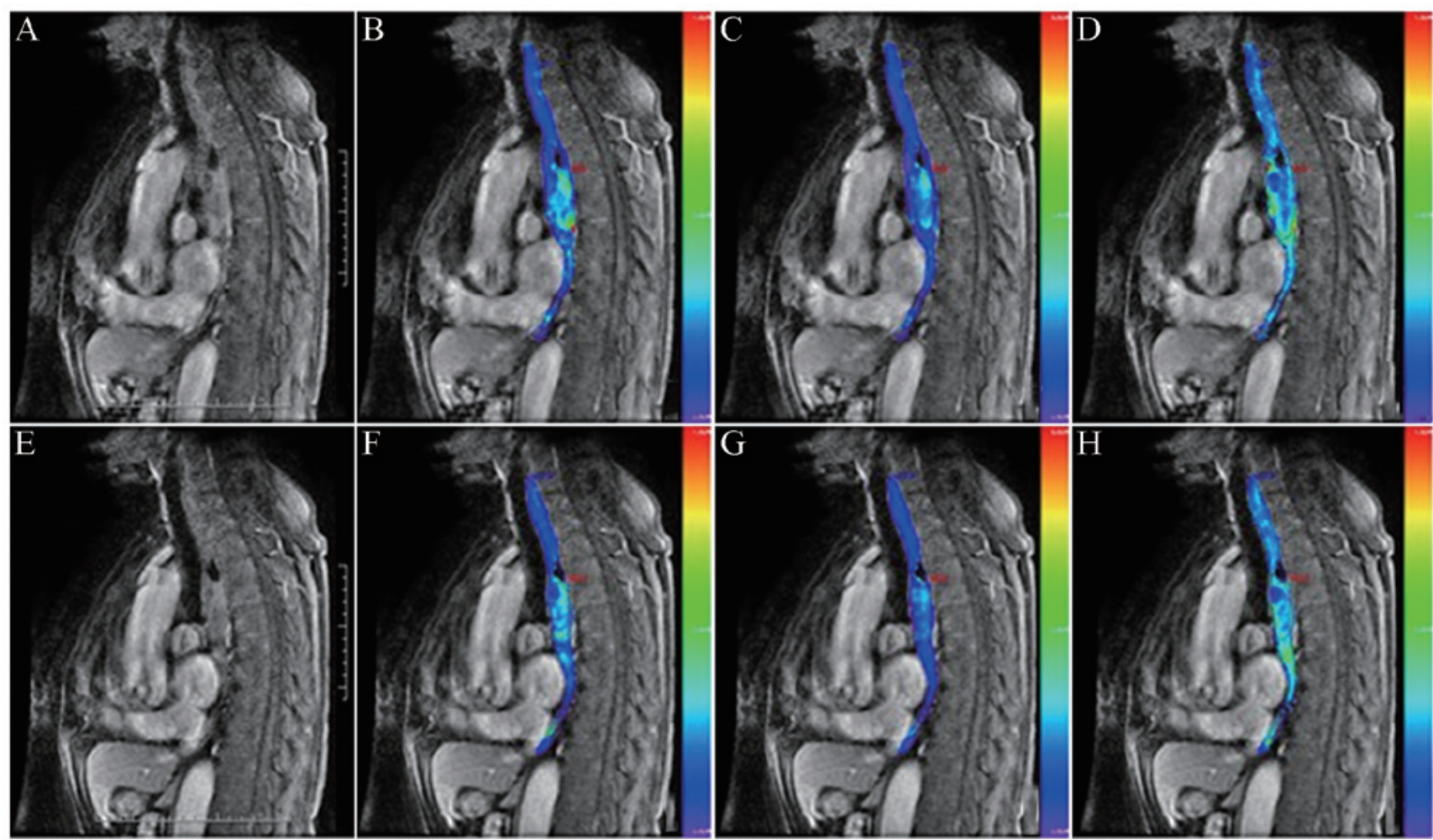

Figure 1. Complete response group (A-D) prior to chemoradiotherapy and (E-H) at 3 weeks post-treatment. (A and E) Dynamic contrast-enhancement of the reinforcement area decreased after 3 weeks of treatment; (B and F) $\mathrm{K}^{\text {trans }}$ pseudocolor images showing that $\mathrm{K}^{\text {trans }}$ values decreased after 3 weeks of treatment; $(C$ and $G) K_{e p}$ pseudocolor images showing that $K_{e p}$ values decreased after 3 weeks of treatment; $(D$ and $H) V_{e}$ pseudocolor images showing that $V_{e}$ values increased after 3 weeks of treatment. $\mathrm{K}^{\text {trans }}$ represents the volume transfer constant and $\mathrm{V}_{\mathrm{e}}$ represents the extravascular extracellular space volume percentage. The display range of $\mathrm{K}_{\mathrm{ep}}$ pseudocolor images was $0.000-5.000 / \mathrm{min}$ and the display range of $\mathrm{V}_{\mathrm{e}}$ was $0.000-1.000 / \mathrm{min}$. $\mathrm{K}_{\mathrm{ep}}$, represents the rate contrast.
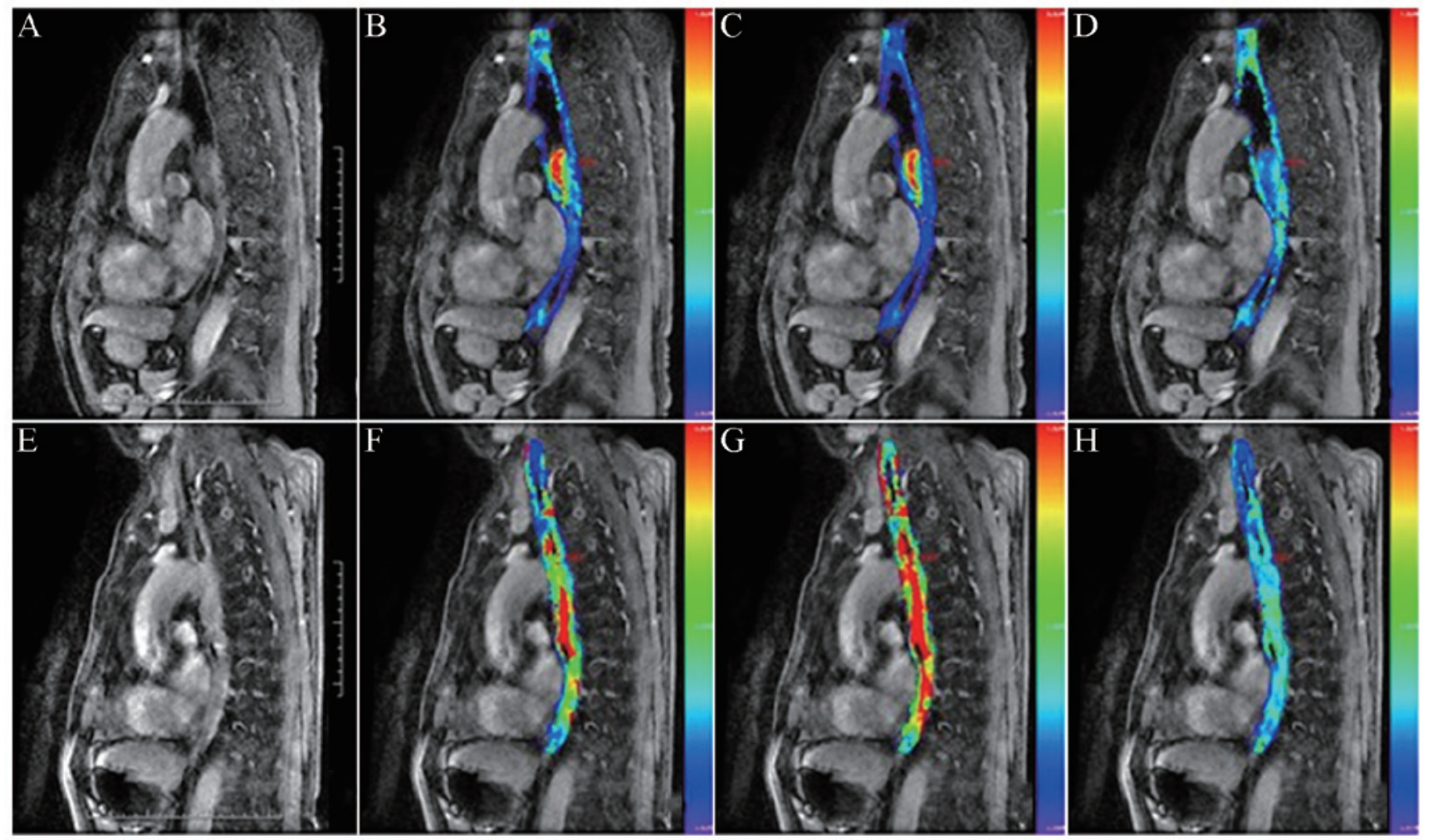

Figure 2. Partial response group (A-D) prior to chemradiotherapy and (E-H) at 3 weeks post-treatment. (A and E) Dynamic contrast-enhancement of the reinforcement area increased after 3 weeks of treatment; (B and F) $K^{\text {trans }}$ pseudocolor images showing that $\mathrm{K}^{\text {trans }}$ values increased after 3 weeks of treatment; $(C$ and $G) K_{e p}$ pseudocolor images showing that $K_{e p}$ values increased after 3 weeks of treatment; (D and $\left.H\right) V_{e}$ pseudocolor images showing that $V_{e}$ values increased after 3 weeks of treatment. $\mathrm{K}^{\text {trans }}$ represents the volume transfer constant and $\mathrm{V}_{\mathrm{e}}$ represents the extravascular extracellular space volume percentage. The display range of $\mathrm{K}_{\mathrm{ep}}$ pseudocolor images was $0.000-5.000 / \mathrm{min}$ and the display range of $\mathrm{V}_{\mathrm{e}}$ was $0.000-1.000 / \mathrm{min}$. $\mathrm{K}_{\mathrm{ep}}$, represents the rate contrast. 
Table I. Comparison of parameter values between the CR and PR groups prior to chemoradiotherapy (mean \pm standard deviation).

\begin{tabular}{lcccr}
\hline Group & Case & $\mathrm{K}^{\text {trans }}(/ \mathrm{min})$ & $\mathrm{K}_{\mathrm{ep}}(/ \mathrm{min})$ & $\mathrm{V}_{\mathrm{e}}$ \\
\hline $\mathrm{CR}$ & 17 & $0.54 \pm 0.17$ & $1.12 \pm 0.46$ & $0.37 \pm 0.14$ \\
PR & 8 & $0.25 \pm 0.11$ & $1.07 \pm 0.37$ & $0.40 \pm 0.22$ \\
U value & & -2.598 & 1.012 & -0.324 \\
P-value & & 0.038 & 0.331 & 0.755
\end{tabular}

$\mathrm{CR}$, complete response; $\mathrm{PR}$, partial response; $\mathrm{K}^{\text {trans }}$, volume transfer constant; $\mathrm{K}_{\mathrm{ep}}$, rate contrast; $\mathrm{V}_{\mathrm{e}}$, the contrast agent percentage in the space of the extracellular fluid.

Table II. Comparison of parameter values between the CR and PR groups at 3 weeks post-chemoradiotherapy treatment (mean \pm standard deviation).

\begin{tabular}{lcccc}
\hline Group & Case & $\mathrm{K}^{\text {trans }}(/ \mathrm{min})$ & $\mathrm{K}_{\mathrm{ep}}(/ \mathrm{min})$ & $\mathrm{V}_{\mathrm{e}}$ \\
\hline $\mathrm{CR}$ & 17 & $0.33 \pm 0.11$ & $0.86 \pm 0.31$ & $0.66 \pm 0.05$ \\
PR & 8 & $0.62 \pm 0.22$ & $1.19 \pm 0.39$ & $0.45 \pm 0.19$ \\
U value & & -3.319 & -1.719 & -2.628 \\
P-value & & 0.006 & 0.119 & 0.021 \\
\hline
\end{tabular}

$\mathrm{CR}$, complete response; $\mathrm{PR}$, partial response; $\mathrm{K}^{\text {trans }}$, volume transfer constant; $\mathrm{K}_{\mathrm{ep}}$, rate contrast; $\mathrm{V}_{\mathrm{e}}$, the contrast agent percentage in the space of the extracellular fluid.

Table III. Relevant receiver operating characteristic parameters of quantitative parameter values predicting an early response prior to and at 3 weeks post-chemoradiotherapy.

\begin{tabular}{|c|c|c|c|c|c|}
\hline Parameter & $\begin{array}{l}\text { Area under } \\
\text { the curve }\end{array}$ & $\begin{array}{c}\text { Maximal } \\
\text { Youden's index }\end{array}$ & $\begin{array}{l}\text { Testing } \\
\text { threshold }\end{array}$ & Susceptibility, \% & Specificity, $\%$ \\
\hline \multicolumn{6}{|c|}{ Prior to chemoradiotherapy } \\
\hline $\mathrm{K}^{\text {trans }}$ & 0.648 & 44.5 & 0.388 & 77.8 & 66.7 \\
\hline $\mathrm{K}_{\mathrm{ep}}$ & 0.407 & 22.3 & 1.083 & 55.6 & 66.7 \\
\hline $\mathrm{V}_{\mathrm{e}}$ & 0.630 & 33.4 & 0.303 & 66.7 & 66.7 \\
\hline \multicolumn{6}{|c|}{ At 3 weeks post-treatment } \\
\hline $\mathrm{K}^{\mathrm{trans}}$ & 0.741 & 33.4 & 0.385 & 66.7 & 66.7 \\
\hline $\mathrm{K}_{\mathrm{ep}}$ & 0.796 & 44.5 & 0.933 & 77.8 & 66.7 \\
\hline $\mathrm{V}_{\mathrm{e}}$ & 0.481 & 11.1 & 0.692 & 44.4 & 66.7 \\
\hline
\end{tabular}

$\mathrm{K}^{\text {trans }}$, volume transfer constant; $\mathrm{K}_{\mathrm{ep}}$, rate contrast; $\mathrm{V}_{\mathrm{e}}$, the contrast agent percentage in the space of the extracellular fluid.

$\mathrm{K}^{\text {trans }}$ and $\mathrm{K}_{\mathrm{ep}}$ in the PR group increased, there was statistical significance between the two groups for these two parameters (both $\mathrm{P}<0.05)$. The values of $\mathrm{V}_{\mathrm{e}}$ in the $\mathrm{CR}$ group increased $(\mathrm{P}<0.05)$, and the values of $\mathrm{V}_{\mathrm{e}}$ in the $\mathrm{PR}$ group increased marginally; however, there was no statistical significance between groups $(\mathrm{P}>0.05)$ (Table II).

ROC analysis of the parameter values prior to chemoradiotherapy and at 3 weeks post-treatment showed that the $\mathrm{K}^{\text {trans }}$ values prior to chemoradiotherapy and $\mathrm{K}^{\text {trans }}$ and $\mathrm{V}_{\mathrm{e}}$ values at 3 weeks post-treatment were the better predictive parameters in the CR group. The areas below the curve were 0.648 , 0.741 and 0.796 , respectively. At 3 weeks post-treatment, the susceptibility and specificity of $\mathrm{K}_{\mathrm{ep}}$ was 77.8 and $66.7 \%$, respectively, (the diagnostic range was 0.933 ) (Table III).

\section{Discussion}

According to the statistical report data on global carcinoma in 2008, China was ranked with the fourth highest morbidity rate for esophageal carcinoma worldwide (1). Squamous carcinoma is the main pathological type of esophagus carcinoma in China, and features high-grade malignancy, rapid development, poor treatment effects and a high recurrence rate (11). Consequently, $80 \%$ of patients are in the intermediate and advanced stages 
when first presenting to a doctor (12). Currently, the best treatment for esophagus carcinoma of intermediate and advanced stages is concurrent chemoradiotherapy (13). Non-invasive imageological examinations are the main method to evaluate the early response of esophagus carcinoma. Clinically, barium meals and computed tomography scans are used to observe the variation in the tumor volume to evaluate the treatment effect. However, it is difficult to reflect the early response of a tumor objectively and accurately, as radiotherapy often causes reactive edema of tissue surrounding the tumor, and the tumor size does not vary markedly or appears as pseudoedema (14). At the molecular level, DCE-MRI takes advantage of dynamics enhancement images and the pharmacokinetics model. It also takes consideration of the fact that the concentration of contrast agent varies as time progresses, and acknowledges the exchange process of contrast agent inside and outside the vessels, thus describing certain hemodynamics information quantitatively, such as the generation and permeability of carcinoma capillaries (15). This technology has been applied to the grading and effect evaluation of certain malignant tumors, including glioma, breast carcinoma and prostate carcinoma (16-18). By analyzing variations in surrounding parameter values of a DCE-MRI pharmacokinetics model in patients with esophageal squamous carcinoma prior to and following chemoradiotherapy, the present study aimed to investigate the assessment and predictive abilities of an early response in primary esophageal carcinoma patients undergoing concurrent chemoradiotherapy.

DCE-MRI quantitative parameters consisted of: i) $\mathrm{K}^{\text {trans }}$ ii) $\mathrm{K}_{\mathrm{ep}}$; and iii) $\mathrm{V}_{\mathrm{e}}$. The three quantitative parameters are linked in the following equation: $\mathrm{K}_{\mathrm{ep}}=\mathrm{K}^{\text {trans }} / \mathrm{V}_{\mathrm{e}}$. According to Tofts pharmacokinetics two compartment model, plasma was selected as the central compartment and EES as the rim compartment, thus deducing the following equation: $\mathrm{Ct}=\mathrm{K}^{\text {trans }}(\mathrm{Cp}(\mathrm{t}) \mathrm{x}$ e$\left.\mathrm{K}_{\mathrm{ep}} \mathrm{x} \mathrm{t}\right)(8)$. In the equation, $\mathrm{Ct}(\mathrm{t})$ was the rate of time of contrast agent concentration inside the tissue. $\mathrm{Cp}(\mathrm{t})$ was the rate of time of contrast agent concentration in the vessels near to the carcinoma. $\mathrm{C}(\mathrm{t})$ and $\mathrm{Cp}(\mathrm{t})$ were obtained respectively from the variation in $\mathrm{T} 1$ signal in the tissues and vessels, and then the $\mathrm{K}^{\text {trans }}, \mathrm{K}_{\mathrm{ep}}$ and $\mathrm{V}_{\mathrm{e}}$ values were obtained through the curve fitting calculation of numerous parameters (9). This technology features the advantages of security, economy and the ability for repetitive use. It can be used to diagnose carcinoma qualitatively, to grade malignancy, to evaluate the effects of carcinoma and to develop antineoplastic drugs (19).

The cellular metabolic cycle is three weeks, and at that time, an early response to chemoradiotherapy should have theoretically appeared. However, the side-effects of chemoradiotherapy may lead to edema. It is difficult to reflect the response of treatment objectively, if only depending on observing the carcinoma morphology. The results of the present study showed that there was a statistical difference between the CR and PR groups for the pharmacokinetics parameter values of $K^{\text {trans }}$ and $V_{e}$ when undergoing chemoradiotherapy for three weeks. Therefore, DCE-MRI could detect the variation in esophageal carcinoma at the microcirculation level. These results were in agreement with those found by Chang et al (20). This study suggested that DCE-MRI quantitative imaging could distinguish between normal esophageal carcinoma and malignant carcinoma, and the $\mathrm{K}^{\text {trans }}$ values of the mass declined markedly prior to and following chemoradiotherapy. According to the study, chemoradiotherapy could inhibit the expression of VEGF in the tumor vessels, thus preventing the generation of new tumor vessels. However, in the present study, it was found that chemoradiotherapy could also inhibit the generation of tumor cells, leading to the increase in the extracellular space and an increase in the volumetric proportion of the EES. This was represented by the increasing $\mathrm{V}_{\mathrm{e}}$ values in the study results. Carcinoma $\mathrm{K}_{\mathrm{ep}}$ values decreased after three weeks of chemoradiotherapy, but the variation was not marked. This had a certain association with the choice of ROI, as the heterogeneity inside the tumor affected the measurement of the results to a certain extent. The data showed that the patients who had higher $\mathrm{K}^{\text {trans }}$ values prior to chemoradiotherapy exhibited a better treatment response compared with those who had lower $\mathrm{K}^{\text {trans }}$ values prior to chemoradiotherapy. This agreed with the previous study results on the chemoradiotherapy response associated with breast, rectal, pancreatic, hepatocellular and renal carcinoma (21-24). After undergoing chemoradiotherapy, the $\mathrm{K}^{\text {trans }}, \mathrm{Ke}_{\mathrm{p}}$ and $\mathrm{V}_{\mathrm{e}}$ values of the 8 cases in the PR group increased slightly in the present study. Therefore, chemoradiotherapy did not change the local blood perfusion of the tumor tissues and the vascular permeability. Consequently, for patients who are not sensitive to chemoradiotherapy, the treatment plan should be adjusted as soon as possible to obtain an effective treatment time. Through comparing the abilities of different parameter values for predicting the early response of esophageal carcinoma patients undergoing chemoradiotherapy, the best parameters after three weeks of treatment were the $\mathrm{K}^{\text {trans }}$ and $\mathrm{K}_{\mathrm{ep}}$ values.

The present study had certain disadvantages: i) The quantity of the sample was small, which may lead to a certain degree of bias in the results; ii) for the patients who did not have a clear esophageal lump, the choice of ROI was not exact; iii) in order to balance space resolution, time resolution was set at $6 \mathrm{sec}$, however, it was able meet the requirement of processing software after Cintool; and iv) there were numerous scan sequences of DCE-MRI, and the scanning parameters were also not consistent. Therefore, the degree of variation in imaging was larger, and this also affected the measurement of the parameter values.

In conclusion, quantitative DCE-MRI allows the perfusion of tumor tissue to be monitored in a non-invasive manner and thus, it may be applied to monitor tissues following radiotherapy treatment for esophageal carcinoma. Furthermore, the quantitative parameters, $\mathrm{K}^{\text {trans }}$ and $\mathrm{K}_{\mathrm{ep}}$, may be used to monitor the early clinical effects of esophageal carcinoma, which may lead to more objective and timely assessment of treatment. However, the $\mathrm{V}_{\mathrm{e}}$ parameter exhibited no clear advantages in assessing treatment efficacy, and thus requires further study.

\section{Acknowledgements}

The authors would like to thank GE Healthcare Life Sciences (Beijing, China) for their technical assistance.

\section{References}

1. Ferlay J, Shin HR, Bray F, Forman D, Mathers C and Parkin DM: Estimates of worldwide burden of cancer in 2008: GLOBOCAN 2008. Int J Cancer 127: 2893-2917, 2010. 
2. Domper Arnal MJ, Ferrández Arenas Á and Lanas Arbeloa Á: Esophageal cancer: Risk factors, screening and endoscopic treatment in Western and Eastern countries. World J Gastroenterol 21: 7933-7943, 2015.

3. He J and Shao K: The epidemiology, current status of management, challenge and future strategy for esophageal cancer in China. Zhong Guo Ai Zheng Za Zhi 21: 501-504, 2011 (In Chinese).

4. Haefner MF, Lang K, Krug D, Koerber SA, Uhlmann L, Kieser M, Debus J and Sterzing F: Prognostic factors, patterns of recurrence and toxicity for patients with esophageal cancer undergoing definitive radiotherapy or chemo-radiotherapy. J Radiat Res 56: 742-749, 2015.

5. Wong RK and Malthaner R: Withdrawn. Combined chemotherapy and radiotherapy (without surgery) compared with radiotherapy alone in localized carcinoma of the esophagus. Cochrane Database Syst Rev 1: CD002092, 2010.

6. Lu WB, Yu JP, Ni XC, Wang J, Jin JH, Deng LH, Deng JZ; Sun ZQ and Sun SP: Relation between tumor pathologic response to concurrent chemo-radiotherapy and changes of serum VEGF level and its influence on the efficacy and prognosis in patients with esophageal carcinoma. Zhong Hua Fang She Yi Xue Yu Fang Hu Za Zhi 33: 299-302, 2013 (In Chinese).

7. Beierle EA, Strande LF and Chen MK: VEGF upregulates Bcl-2 expression and is associated with decreased apoptosis in neuroblastoma cells. J Pediatr Surg 37: 467-471, 2002.

8. Tofts PS, Brix G, Buckley DL, Evelhoch JL, Henderson E, Knopp MV, Larsson HB, Lee TY, Mayr NA, Parker GJ, et al Estimating kinetic parameters from dynamic contrast-enhanced T(1)-weighted MRI of a diffusable tracer: Standardized quantities and symbols. J Magn Reson Imaging 10: 223-232, 1999.

9. Oberholzer K, Pohlmann A, Schreiber W, Mildenberger P, Kunz P, Schmidberger H, Junginger T and Düber C: Assessment of tumor microcirculation with dynamic contrast-enhanced MRI in patients with esophageal cancer: Initial experience. J Magn Reson Imaging 27: 1296-1301, 2008.

10. Eisenhauer EA, Therasse P, Bogaerts J, Schwartz LH, Sargent D, Ford R, Dancey J, Arbuck S, Gwyther S, Mooney M, et al: New response evaluation criteria in solid tumours: Revised RECIST guideline (version 1.1). Eur J Cancer 45: 228-247, 2009.

11. Cortés González R and Villaseñor Caloca R: Esophageal cancer. Rev Gastroenterol Mex 62: 149-159, 1997 (In Spanish).

12. Greer SE, Goodney PP, Sutton JE and Birkmeyer JD: Neoadjuvant chemoradiotherapy for esophageal carcinoma: A meta-analysis. Surgery 137: 172-177, 2005

13. al-Sarraf M, Martz K, Herskovic A, Leichman L, Brindle JS, Vaitkevicius VK, Cooper J, Byhardt R, Davis L and Emami B: Progress report of combined chemoradiotherapy versus radiotherapy alone in patients with esophageal cancer: An intergroup study. J Clin Oncol 15: 277-284, 1997.
14. Yoon DH, Jang G, Kim JH, Kim YH, Kim JY, Kim HR, Jung HY, Lee GH, Song HY, Cho KJ, et al: Randomized phase 2 trial of S1 and oxaliplatin-based chemoradiotherapy with or without induction chemotherapy for esophageal cancer. Int J Radiat Oncol Biol Phys 91: 489-496, 2015.

15. Shin SU, Lee JM, Yu MH, Yoon JH, Han JK, Choi BI, Glaser KJ and Ehman RL: Prediction of esophageal varices in patients with cirrhosis: Usefulness of three-dimensional MR elastography with echo-planar imaging technique. Radiology 272: 143-153, 2014.

16. Jia ZZ, Zhang J, Tang WJ, Wu XH, Gu HM, Geng DY and Chen XR: Assessing the microvascular permeability of brain glioma by DCE-MRI. Zhong Guo Yi Xue Ji Suan Ji Cheng Xiang Za Zhi 19: 293-297, 2013 (In Chinese).

17. Esposito A, Palmisano A, Maffi P, Malosio ML, Nano R, Canu T, De Cobelli F, Piemonti L, Ironi G, Secchi A and Del Maschio A: Liver perfusion changes occurring during pancreatic islet engraftment: A dynamic contrast-enhanced magnetic resonance study. Am J Transplant 14: 202-209, 2014.

18. He W, Liu Y, Liu JY and Lu M: Prostate cancer: Diagnostic value of quantitative analysis by dynamic contrast-enhanced MR at 3.0 T. Zhong Hua Fang She Xue Za Zhi 48: 215-218, 2014 (In Chinese)

19. Zhao LY, Zhang RZ, Zhou CW, Li J and Wang L: Quantitative dynamic contrast enhanced MR in the prediction of response in breast cancer patients undergoing neoadjuvant chemotherapy. Zhong Hua Fang She Xue Za Zhi 47: 704-708, 2013 (In Chinese).

20. Chang EY, Li X, Jerosch-Herold M, Priest RA, Enestvedt CK, $\mathrm{Xu}$ J, Springer CS Jr and Jobe BA: The evaluation of esophageal adenocarcinoma using dynamic contrast-enhanced magnetic resonance imaging. J Gastrointest Surg 12: 166-175, 2008.

21. Padhani AR, Hayes C, Assersohn L, Powles T, Makris A, Suckling J, Leach MO and Husband JE: Prediction of clinicopathologic response of breast cancer to primary chemotherapy at contrast-enhanced MR imaging: Initial clinical results. Radiology 239: 361-374, 2006.

22. George ML, Dzik-Jurasz AS, Padhani AR, Brown G, Tait DM, Eccles SA and Swift RI: Non-invasive methods of assessing angiogenesis and their value in predicting response to treatment in colorectal cancer. Br J Surg 88: 1628-1636, 2001.

23. Akisik MF, Sandrasegaran K, Bu G, Lin C, Hutchins GD and Chiorean EG: Pancreatic cancer: Utility of dynamic contrast-enhanced MR imaging in assessment of antiangiogenic therapy. Radiology 256: 441-449, 2010.

24. Hahn OM, Yang C, Medved M, Karczmar G, Kistner E, Karrison T, Manchen E, Mitchell M, Ratain MJ and Stadler WM: Dynamic contrast-enhanced magnetic resonance imaging pharmacodynamic biomarker study of sorafenib in metastatic renal carcinoma. J Clin Oncol 26: 4572-4578, 2008. 